\title{
Scientometric assessment of drugs for chronic pain, 1979-20 I3: rapid growth of publications, paucity of successful drugs
}

This article was published in the following Dove Press journal:

Journal of Pain Research

20 August 2014

Number of times this article has been viewed

\section{Igor Kissin}

Department of Anesthesiology, Perioperative and Pain Medicine, Brigham and Women's Hospital, Harvard Medical School, Boston, MA, USA
Correspondence: Igor Kissin Department of Anesthesiology, Brigham and Women's Hospital, 75 Francis Street, Boston, MA 02115, USA

$\mathrm{Tel}+\mathrm{I} 6177325052$

Fax + I 6177340682

Email kissin@zeus.bwh.harvard.edu
Abstract: The aim of this study was to find signs of progress in the pharmacotherapy of chronic pain over the past 35 years using scientometric analysis. The following scientometric indices were used: 1) popularity index, representing the share of articles on a specific drug(s) relative to all articles in the field of chronic pain; 2) index of change, representing the degree of growth in publications on a topic from one period to the next; 3 ) index of expectations, representing the ratio of the number of articles on a topic in the top 20 journals relative to the number of articles in all $(>5,000)$ biomedical journals covered by PubMed; and 4) index of ultimate success, representing a publication outcome when a new drug takes the place of a common drug previously used for the same purpose. Publications on 55 drugs used in the treatment of chronic pain were assessed during seven 5-year periods, from 1979 to 2013. The rate of rise in the number of publications on chronic pain was exponential, with an increase of nearly ninefold from 2,346 articles over the 5-year period 1979-1983 to 21,095 articles in 2009-2013. However, despite this huge increase in publications, our scientometric analysis did not reveal signs of really successful drugs in this field. For the 2009-2013 period, the popularity index had a meaningful magnitude (from 0.5-2.8) for only 13 of 55 drugs. Five of them were opioids, including morphine, which had the highest index value of all drugs (2.8). None of the drugs had a high index of expectations in 2009-2013. The index of ultimate success was positive only with triptans in the relatively limited area of acute treatment of migraine. As a result, despite rapid growth in the number of publications, our scientometric analysis did not reveal signs of substantial progress in the field of pharmacotherapy for chronic pain.

Keywords: anticonvulsants, antidepressants, headache, lower-back pain, migraine, neuropathic pain, NSAIDs, opioids, osteoarthritis, postherpetic neuralgia, triptans

\section{Introduction}

A recent report from the US Institute of Medicine's Committee on Pain Relief indicated that more than 116 million Americans (about 37\% of the population) have pain that persists for weeks to years. The most significant costs of this epidemic are associated with chronic pain, ${ }^{1}$ which is one of the most widely cited conditions underlying disability among older adults. ${ }^{2}$

The scientometric assessments of drugs have been reported previously in a number of publications..$^{3-7}$ Some of the indices based on such assessments were suggested as signs demonstrating progress in the pharmacotherapy of pain. The link between the number of publications and progress in pharmacotherapy is inherently weak. It is enough to mention that the mere number of publications does not differentiate between publications characterizing a drug in positive and negative ways. Sometimes after a 
drug introduction, due to the possible discovery of unexpected adverse effects, a significant number of articles can be devoted to the problems associated with its administration. ${ }^{6}$ Nevertheless, some of the scientometric indices can be used to indicate certain changes in the related pharmacotherapy. Such indices may provide an additional support to the conclusions based on good-quality evidence obtained with randomized controlled trials. The aim of the current study was to find signs of progress in the pharmacotherapy of chronic pain using scientometric analysis.

\section{Materials and methods}

The following publication parameters ${ }^{3-7}$ were used as signs of progress in the pharmacotherapy of chronic pain.

\section{Popularity index}

The popularity index (PI) is the share of articles on a specific topic relative to all articles in the field of chronic pain (chronic pain OR neuropathic pain OR neuralgia OR headache disorders [Medical Subject Headings $\{\mathrm{MeSH}\}$ term]). A specific threshold of $0.5 \%$ (arbitrary) was used to select topics for which the number of publications (2009-2013) reached a notable level.

\section{Index of change}

The index of change (IC) is the change in number of publications on a drug during a 5-year period compared to the previous 5-year period. It reflects the change in general interest in a topic. The specific threshold used for this index was the growth beyond the increase in number of publications in the whole field of chronic pain during the same time interval.

\section{Index of expectations}

The index of expectations (IE) or top journal selectivity index, is the ratio of the number of all types of articles on a particular topic in the top 20 journals relative to the number of articles in all $(>5,000)$ biomedical journals covered by PubMed over 5 years. It reflects the level of interest in a topic in the top journals. An index value $\geq 10$ was selected to represent a high expectation of success. The 20 top journals were selected based on two factors: 1) their rank sorted by impact factor, as indicated by Journal Citation Reports for 2012; and 2 ) the journal's specialty area. They included pharmacology, anesthesiology, pain, neurology (ten journals), and general biomedical journals (also ten): Anesthesiology, Annals of Internal Medicine, Annals of Neurology, British Journal of Anaesthesia, British Medical Journal, Journal of the American Medical Association, Journal of Clinical Investigation,
Journal of Clinical Pharmacology and Therapeutics, Journal of Pharmacology and Experimental Therapeutics, Lancet, Lancet - Neurology, Nature, Nature - Medicine, Nature Reviews - Drug Discovery, Nature Reviews - Neuroscience, New England Journal of Medicine, Pain, Proceedings of the National Academy of Science of the United States of America, Science, and Trends in Pharmacological Sciences.

\section{Index of ultimate success}

The index of ultimate success (IUS) is a publication outcome indicating that a new drug (or a group of drugs) has taken the place of a drug that was previously commonly used for the same purpose. It is measured by the degree of decline in the PI of an old, supplanted drug. A decline of the PI of a supplanted drug by $50 \%$ or more during an interval of 10-20 years was selected to represent a positive IUS.

The articles were counted using the National Library of Medicine's PubMed website (http://www.ncbi.nlm.nih.gov/ pubmed), which covers over 21 million journal articles in biomedicine. Drugs used for the treatment of chronic pain were selected from various sources. ${ }^{8-15}$ The following 55 drugs were searched: acetaminophen, almotriptan, amitriptyline, aspirin, atenolol, buprenorphine, carbamazepine, celecoxib, clonazepam, codeine, desipramine, diclofenac, dihydroergotamine, divalproex, doxepin, dronabinol, duloxetine, eletriptan, ergotamine, flunarizine, fluoxetine, flurbiprofen, frovatriptan, gabapentin, hydrocodone, hydromorphone, ibuprofen, imipramine, indomethacin, ketoprofen, lamotrigine, methadone, methysergide, mexiletine, morphine, nalbuphine, naproxen, naratriptan, oxycodone, phenytoin, piroxicam, pregabalin, propranolol, rizatriptan, sumatriptan, tapentadol, timolol, topical capsaicin, topiramate, tramadol, transdermal fentanyl, venlafaxine, verapamil, ziconotide, and zolmitriptan (MeSH terms indicated in Table 1). The criterion for selection of a particular drug for analysis was the level of its PI in 2009-2013. If the PI was $>0.5$, the drug was assessed using the IC, IE, and IUS.

An individual drug name or the name of a class of drugs (such as anticonvulsants [MeSH term], antidepressants, opioids, or NSAIDs [nonsteroidal anti-inflammatory drugs]) was entered in the search box with the following keyword combination: chronic pain OR neuropathic pain OR neuralgia OR headache disorders (MeSH term). In addition to the terms related to the main field of chronic pain, several related specific subfields (areas) were assessed separately. As a result, the following keywords or keyword combinations were entered in the search box: migraine, postherpetic neuralgia, osteoarthritis (AND pain), or low back pain (MeSH term). 


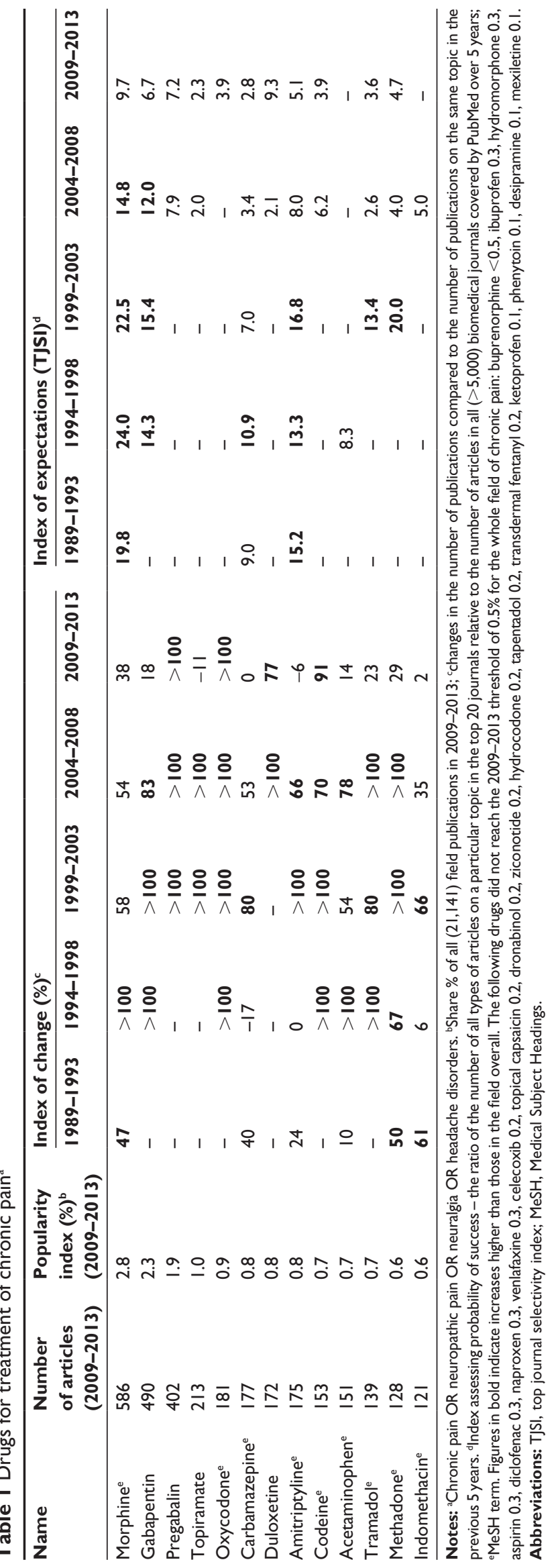

Filters for languages (English) were used. All types of articles were taken into account.

\section{Results}

Of 55 drugs used in chronic pain management and included in the search, the 13 with a PI $>0.5 \%$ (in 2009-2013) are presented in Table 1. Five of them are opioids, four drugs are anticonvulsants, and the rest are two antidepressants, one NSAID, and acetaminophen. Seventeen of the 55 included in the search drugs had PIs between 0.5 and 0.1, including six NSAIDs and four opioids. During 2009-2013, none of the drugs listed in Table 1 demonstrated an IE of $\geq 10$. During the same period, only four drugs had notable increases in the IC (above the increases in the whole field of chronic pain): pregabalin, oxycodone, duloxetine, and codeine.

The relative roles of major classes of drugs in several specific subfields (areas) of chronic pain are presented in Table 2. Although opioids, NSAIDs, anticonvulsants, and antidepressants may be used in all areas of chronic pain, their predominant applications are rather specific. For example, let us compare postherpetic neuralgia and osteoarthritis pain. In 2009-2013, the PI of anticonvulsants for postherpetic neuralgia reached 20.3, but was only 0.5 for pain in osteoarthritis. Conversely, the PI of NSAIDs in osteoarthritis was 9.0, but only 3.3 in postherpetic neuralgia. The only class of drugs that was used very selectively is triptans, mostly as abortive medications for the treatment of migraine. Therefore, the 2009-2013 PI of drugs for the treatment of migraine is presented separately in Table 3. Sumatriptan's PI was the highest -4.5 - and six other triptans had PIs ranging from 1.1 (rizatriptan) to 0.4 (eletriptan). Along with triptans, three anticonvulsants (topiramate, PI 4.0; divalproex, PI 1.7; and gabapentin, PI 0.6), three NSAIDs (naproxen, PI 1.0; aspirin, PI 0.9; and ibuprofen, PI 0.6), and acetaminophen (PI 0.9) appeared most often in migraine-related publications.

The 1979-2013 time course of PIs for major classes of drugs used for the treatment of chronic pain is presented in Figure 1. Over the past 35 years, there have been no important changes in PI for anticonvulsants, antidepressants, or NSAIDs. NSAIDs had a PI of 3.4 in the first 5-year period (1979-1983), and 3.5 in the most recent period (2009-2013). PI for antidepressants declined, though only by about $30 \%$, from 4.7 (1979-1983) to 3.5 (1989-1993) and then to 3.3 (2009-2013). Specifically, amitriptyline's PI declined from 1.1 (1984-1988) to 0.8 (2009-2013). The PI for anticonvulsants was 3.7 in 1979-1983, and in 2004-2008 it increased to 7.0; however, it then declined to 5.0 in 2009-2013. The aforementioned relative stability of PI is especially 
Table 2 2009-2013 popularity index for major classes of drugs used in different subfields of chronic pain

\begin{tabular}{lllll}
\hline & Migraine & $\begin{array}{l}\text { Postherpetic } \\
\text { neuralgia }\end{array}$ & $\begin{array}{l}\text { Osteoarthritis } \\
\text { AND pain }\end{array}$ & $\begin{array}{l}\text { Lower-back } \\
\text { pain }\end{array}$ \\
\hline $\begin{array}{l}\text { Popularity index (\%) } \\
\text { Opioids }\end{array}$ & 1.6 & & & \\
NSAIDs (OR acetaminophen) & 4.2 & 9.5 & 4.0 & 3.5 \\
Anticonvulsants & 5.5 & 3.3 & 9.0 & 2.4 \\
Antidepressants & 1.8 & 20.3 & 0.5 & 0.5 \\
$\quad$ Triptans & 10.3 & 4.8 & 0.7 & 0.7 \\
Total number of pain-subfield articles & 6,111 & - & - & - \\
\hline
\end{tabular}

Abbreviation: NSAIDs, nonsteroidal anti-inflammatory drugs.

impressive if the rate of growth in the number of articles related to chronic pain is taken into account. As indicated in Figure 1 and stated earlier, from 1979-1983 to 2009-2013, the number of articles per 5-year period increased ninefold. The most significant change in the PI reflected by Figure 1 was the continuous rise in the PI of opioids: from 4.1 in 1989-1993 to 9.2 in 2009-2013.

The time course of PI for triptans, a class of drugs used predominantly for abortive treatment of migraine, is presented in Table 4. In 1999-2003, the PI of triptans reached 19.9 among migraine-related articles, after which it declined, but not below 10.3 (2009-2013). Two drugs that before the introduction of triptans were used for abortive therapy of migraine - ergotamine and dihydroergotamine - showed

Table 3 2009-20I3 popularity index of drugs for treatment of migraine

\begin{tabular}{|c|c|c|}
\hline Name & $\begin{array}{l}\text { Number } \\
\text { of articles }\end{array}$ & $\begin{array}{l}\text { Popularity } \\
\text { index (\%)* }\end{array}$ \\
\hline Sumatriptan \# & 277 & 4.5 \\
\hline Topiramate & 246 & 4.0 \\
\hline Divalproex & 104 & $\mathrm{I} .7$ \\
\hline Amitriptyline & 67 & I.I \\
\hline Dihydroergotamine ${ }^{\#}$ & 67 & I.I \\
\hline Rizatriptan & 66 & I.I \\
\hline Propranolol ${ }^{\#}$ & 65 & I.I \\
\hline Naproxen $\#$ & 61 & 1.0 \\
\hline Ergotamine ${ }^{\#}$ & 58 & 1.0 \\
\hline Aspirin $\#$ & 57 & 0.9 \\
\hline Zolmitriptan & 57 & 0.9 \\
\hline Acetaminophen \# & 54 & 0.9 \\
\hline Almotriptan & 52 & 0.8 \\
\hline Frovatriptan & 50 & 0.8 \\
\hline Flunarizine & 40 & 0.6 \\
\hline Gabapentin & 39 & 0.6 \\
\hline lbuprofen $\#$ & 36 & 0.6 \\
\hline Naratriptan & 29 & 0.5 \\
\hline \multicolumn{3}{|c|}{$\begin{array}{l}\text { Notes: *Share of all }(6,111) \text { migraine-subfield publications in } 2009-2013 \text {; } \# \text { MeSH } \\
\text { term. The following drugs did not reach the } 2008-2013 \text { threshold of } 0.5 \% \text { for } \\
\text { the whole subfield of migraine: eletriptan } 0.4 \text {, lamotrigine } 0.4 \text {, carbamazepine } 0.4 \text {, } \\
\text { verapamil } 0.4 \text {, metoprolol } 0.3 \text {, methysergide } 0.2 \text {, timolol } 0.2 \text {, fluoxetine } 0.2 \text {, } \\
\text { pregabalin } 0.2 \text {, atenolol } 0.1 \text {. }\end{array}$} \\
\hline
\end{tabular}

a dramatic decrease in combined PI: from 10.0 and 8.2 (1974-1978 and 1979-1983) to 1.8 (2009-2013). At the same time, the PI of anticonvulsants, drugs used for migraine prevention, did not decline with the introduction of triptans (Table 4).

Selective decline in the PI of supplanted drugs can be regarded as the most reliable indication of success of a new, supplanting agent(s) and can be measured by the IUS. In the 15 years after the introduction of triptans, their IUS reached $67 \%$ (the decline of ergotamine/dihydroergotamine PI). Table 5 presents the IUS of triptans in comparison with several other classes of drugs (proton-pump inhibitors, angiotensin-converting enzyme inhibitors, and triazole antifungal drugs). The table indicates that it usually takes $10-15$ years to achieve an IUS of 50 or more.

Table 6 represents the 1979-2013 time course of changes (IC) in publications on chronic pain 1) in general and 2) in the specific migraine area, and 3) compares them with changes in all medicobiological publications covered by PubMed in an article-type category - "journal article". The table clearly indicates that publication efforts in the field of chronic pain did not lag behind that in all medicobiological areas (combined) in any of the eight 5-year periods starting with 1979-1983. In most time periods, IC was significantly higher than that with all medicobiological publications in general, and its 5-year increases varied from a minimum of 24 (1989-1993) to a maximum of 66 (1999-2003). It is also of interest that for the two 5-year periods preceding the discovery of triptans (1979-1983 and 1984-1988), the IC for migraine-specific publications was not higher than for the chronic pain field in general.

\section{Discussion}

\section{Popularity index}

The results indicate that among drugs used for the treatment of chronic pain, morphine was the subject of the highest number of current publications. In 2009-2013, the share of 


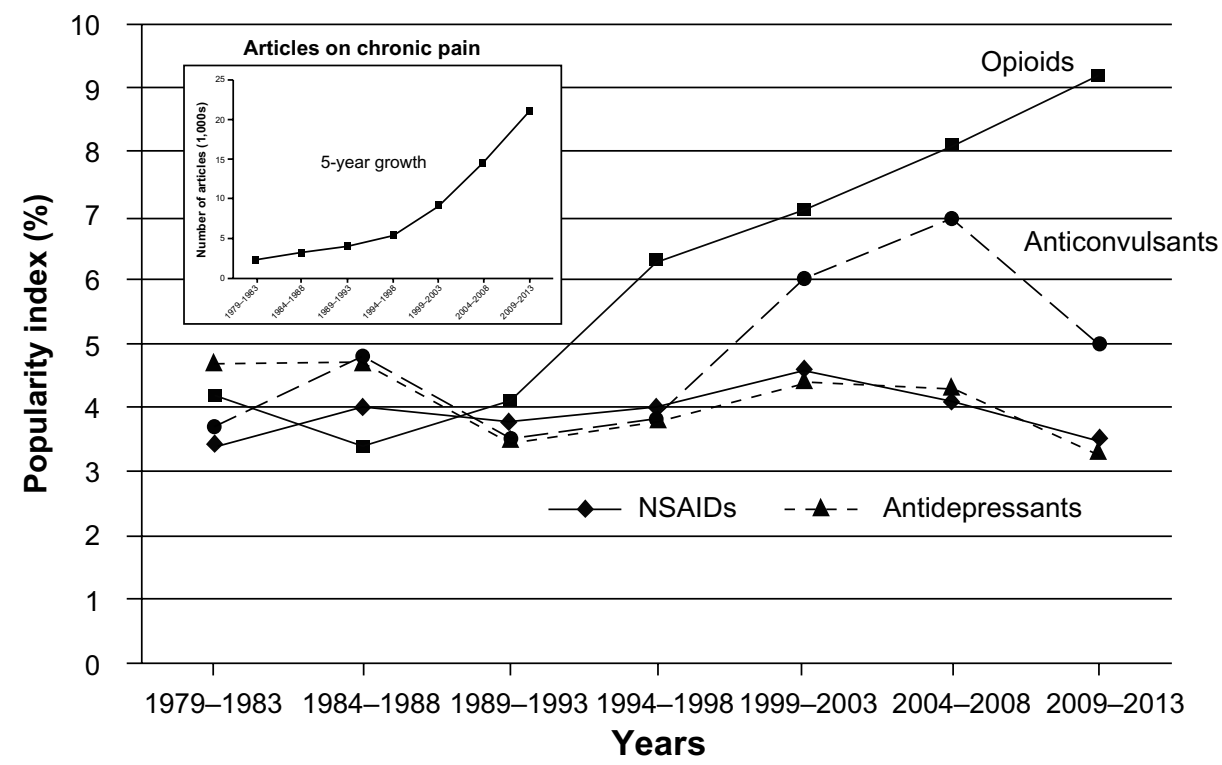

Figure I Time course of popularity index for major classes of drugs used for the treatment of chronic pain. The popularity index represents the share (percentage) of articles on a specific class of drugs relative to all articles in the field of chronic pain during a 5-year period. The inset shows the 5-year rate of growth in the actual number of articles. Abbreviation: NSAIDs, nonsteroidal anti-inflammatory drugs.

articles related to this drug was $2.8 \%$ of articles published in the whole field of chronic pain (PI 2.8). Although this number is much lower than that associated with the morphine PI for the treatment of acute pain $-11.6^{7}$ - the persistence of morphine as the most popular drug in the field of chronic pain can only be regarded as a sign of failure of progress in the pharmacotherapy of chronic pain. Systematic reviews on opioid treatment of chronic nonmalignant pain have found insufficient evidence to make a conclusion on the long-term efficacy of such treatment. ${ }^{16-19}$ In addition, even in relatively short-term therapy, opioids are not sufficiently effective. For example, in the treatment of neuropathic pain, the $\geq 50 \%$ number-needed-to-treat index of opioids is approximately 2.5. ${ }^{20}$ That means that only one of two or three patients will achieve pain relief, and that relief will be only partial. The other important problem in the use of opioids for chronic pain is their safety, especially in terms of risk of addiction and overdose death, which was clearly neglected..$^{21}$ The US Food and Drug Administration (FDA) even created its Risk Evaluation and Mitigation Strategies for opioids to deal with potential safety problems. ${ }^{22}$

Although opioids have been used for the treatment of persistent pain for centuries, in 1960-1980 they were used for chronic nonmalignant pain infrequently. ${ }^{23}$ This explains the almost-complete absence of publications on the use of morphine for chronic pain before 1983. However, in the 1990s, as indicated in Table 1, the number of morphine-related articles increased rather dramatically. The other indication of

Table 4 1979-20I3 time course of popularity index (PI) for major classes of drugs used for treatment of migraine

\begin{tabular}{|c|c|c|c|c|c|c|c|c|c|}
\hline \multirow[t]{4}{*}{ Years } & \multirow{4}{*}{$\begin{array}{l}\text { Number of } \\
\text { all migraine- } \\
\text { related articles }\end{array}$} & \multicolumn{8}{|c|}{ Drug-related articles } \\
\hline & & \multicolumn{2}{|l|}{ Triptans } & \multirow{2}{*}{\multicolumn{2}{|c|}{$\begin{array}{l}\text { Ergotamine OR } \\
\text { dihydroergotamine }\end{array}$}} & \multirow{2}{*}{\multicolumn{2}{|c|}{$\begin{array}{l}\text { NSAIDs OR } \\
\text { acetaminophen }\end{array}$}} & \multirow{2}{*}{\multicolumn{2}{|c|}{ Anticonvulsants }} \\
\hline & & \multirow[t]{2}{*}{ Number } & \multirow[t]{2}{*}{ PI (\%) } & & & & & & \\
\hline & & & & Number & PI (\%) & Number & PI (\%) & Number & PI (\%) \\
\hline $1974-1978$ & 758 & - & - & 76 & 10.0 & 33 & 4.4 & 19 & 2.5 \\
\hline $1979-1983$ & 1,018 & - & - & 84 & 8.2 & 54 & 5.3 & 20 & 2.0 \\
\hline |984-1988 & $\mathrm{I}, 370$ & 47 & 3.4 & 86 & 6.3 & 83 & 6.1 & 79 & 5.8 \\
\hline 1989-1993 & 1,740 & 204 & 11.7 & 117 & 6.7 & 109 & 6.3 & 64 & 3.7 \\
\hline $1994-1998$ & $2,37 \mid$ & 445 & 18.8 & 136 & 5.7 & $|3|$ & 5.5 & 100 & 4.2 \\
\hline 1999-2003 & 3,526 & 701 & 19.9 & $13 \mid$ & 3.7 & 202 & 5.7 & 179 & 5.1 \\
\hline 2004-2008 & 5,077 & 742 & 14.6 & 113 & 2.2 & 249 & 4.9 & 356 & 7.0 \\
\hline $2009-2013$ & 6,111 & 629 & 10.3 & 109 & 1.8 & 260 & 4.2 & 334 & 5.5 \\
\hline
\end{tabular}

Abbreviation: NSAIDs, nonsteroidal anti-inflammatory drugs. 
Table 5 Index of drug success, expressed as degree of decline in popularity of an old drug used for the same purpose

\begin{tabular}{|c|c|c|c|c|c|c|c|c|}
\hline \multicolumn{2}{|l|}{ New family of drugs } & \multirow{3}{*}{$\begin{array}{l}\text { Disorder or } \\
\text { disease }\end{array}$} & \multirow{3}{*}{$\begin{array}{l}\text { Old (supplanted) } \\
\text { drug(s) }\end{array}$} & \multirow{2}{*}{\multicolumn{5}{|c|}{$\begin{array}{l}\text { Decline of PI of supplanted drugs } \\
\text { at different time intervals (years since } \\
\text { new drug introduction) }\end{array}$}} \\
\hline \multirow{2}{*}{$\begin{array}{l}\text { Group name } \\
\text { (first drug) }\end{array}$} & \multirow{2}{*}{$\begin{array}{l}\text { Year of first } \\
\text { drug approval }\end{array}$} & & & & & & & \\
\hline & & & & (5) & $(10)$ & (15) & (20) & (25) \\
\hline \multirow[t]{2}{*}{ Triptans (sumatriptan) } & 1992 & Migraine & Ergotamine OR & $15 \%$ & $45 \%$ & $67 \%$ & $73 \%$ & - \\
\hline & & & dihydroergotamine & & & & & \\
\hline \multirow[t]{2}{*}{ PPIs (omeprazole) } & 1990 & Gastroesophageal & Histamine & $32 \%$ & $55 \%$ & $71 \%$ & - & - \\
\hline & & reflux & $\mathrm{H}_{2}$ antagonists & & & & & \\
\hline ACE inhibitors (captopril) & $198 \mid$ & Heart failure & Digoxin & $14 \%$ & $29 \%$ & $51 \%$ & $74 \%$ & $84 \%$ \\
\hline Triazoles (itraconazole) & 1994 (1984) & Mycoses & Imidazoles & $32 \%$ & $42 \%$ & $45 \%$ & $55 \%$ & - \\
\hline
\end{tabular}

Abbreviations: PI, popularity index; PPIs, proton-pump inhibitors; ACE, angiotensin-converting enzyme.

the rise in popularity of opioids for the treatment of chronic pain is the number of opioids with PIs $>0.5$ : of 13 drugs at that level, five are opioids. All of them except tramadol were introduced more than 50 years ago. Figure 1, which presents the time course of PI for opioids as a class of drug in general, also confirms continuous growth in the popularity of opioids for the treatment of chronic pain.

Table 1 indicates that three drugs with high PIs (but lower than that of morphine) are anticonvulsants: gabapentin, pregabalin, and topiramate (PIs of 2.3, 1.9, and 1.0, respectively). Figure 1 shows that the popularity of anticonvulsants in general rose in 1999-2003 and 2004-2008 (with PIs of 6.0 and 7.0, respectively) and then declined to 5.0 in 2009-2013 (almost the same level as anticonvulsants had in 1984-1988). The rise in the PI of anticonvulsants in 1999-2003 and 2004-2008 coincided with the FDA approval of three anticonvulsants for indications related to some types of chronic pain (gabapentin in 2002, pregabalin in 2004, and topiramate in 2004). Duloxetine and amitriptyline are two antidepressants with a PI higher than 0.5 (Table 1). Because triptans were used mostly for migraine, the PI for migraine-related articles was determined separately. Table 3 indicates that in 2009-2013, sumatriptan had the highest number of publications - PI 4.5. Six other triptans had much lower popularity: the PI varied from 1.1 (rizatriptan) to 0.4 (eletriptan).

\section{Indices of expectations and change}

The IE reflects expectations regarding a drug's prospects. In 2009-2013, none of the 13 most popular drugs had an IE higher than 10 (Table 1), and only four had an IE above 6: morphine (9.7), duloxetine (9.3), pregabalin (7.2), and gabapentin (6.7). The IE for morphine is declining (from 24.0 in 1994-1998), and is presently fueled to a great extent by controversy related to opioid addiction and unintentional overdose with the long-term treatment of chronic pain. The high IE value for gabapentin before 2009 was mostly due to the prolonged period of opinion formation that is typical with a new drug.

As far as the IC is concerned, in 2009-2013 only four of the 13 most popular drugs showed increases beyond that for the whole area of chronic pain: pregabalin $(>100)$, oxycodone (>100), codeine (91), and duloxetine (77). The pregabalin and duloxetine values are mostly due to the fact

Table 6 1974-20I3 time course of changes (IC) for articles on chronic pain

\begin{tabular}{|c|c|c|c|c|c|c|}
\hline \multirow[t]{3}{*}{ Years } & \multicolumn{2}{|c|}{ All chronic pain articles } & \multicolumn{2}{|c|}{ Migraine-only articles } & \multirow{2}{*}{\multicolumn{2}{|c|}{$\begin{array}{l}\text { PubMed "journal article” } \\
\text { category }\end{array}$}} \\
\hline & \multirow[t]{2}{*}{ Number } & \multirow[t]{2}{*}{ IC (\%) } & \multirow[t]{2}{*}{ Number } & \multirow[t]{2}{*}{ IC (\%) } & & \\
\hline & & & & & Number & IC (\%) \\
\hline $1974-1978$ & 1,685 & - & 758 & - & 843,690 & - \\
\hline 1979-1983 & 2,346 & 39 & 1,018 & 34 & $1,005,817$ & 19 \\
\hline 1984-1988 & 3,275 & 40 & 1,370 & 35 & I,273,426 & 27 \\
\hline 1989-1993 & 4,047 & 24 & $\mathrm{I}, 740$ & 27 & $1,559,433$ & 22 \\
\hline 1994-1998 & 5,573 & 38 & 2,371 & 36 & $\mathrm{I}, 805,947$ & 16 \\
\hline 1999-2003 & 9,247 & 66 & 3,526 & 49 & $2,209,228$ & 22 \\
\hline 2004-2008 & 14,842 & 60 & 5,077 & 44 & $2,910,760$ & 32 \\
\hline 2009-20I3 & 21,095 & 42 & 6,111 & 20 & $3,909,638$ & 34 \\
\hline
\end{tabular}

Abbreviation: IC, index of change. 
that they are relatively new drugs. An increased IC with oxycodone and codeine is to a great extent related to the controversy associated with opioids in general.

\section{Index of ultimate success}

The most important outcome of the introduction of a new drug is the slow decline of number of articles in medicobiological professional journals about an old drug that previously was dominantly in use for the same purpose. Figure 1 indicates that there was no such decline with major classes of old drugs used for the treatment of chronic pain (anticonvulsants, antidepressants, or NSAIDs). On the contrary, opioids (not regarded as the best choice for the treatment of chronic pain in 1960-1980) began to gain popularity for this indication. Of all drugs used for the treatment of chronic pain, only triptans had the distinction of a positive IUS; however, that was for a limited migraine-specific indication. Ergotamine and dihydroergotamine, which were dominant for this purpose in 1974-1978, were actually supplanted by triptans in 1979-1983. At the same time, however, triptans did not supplant anticonvulsants or NSAIDs (Table 4).

Figure 2 illustrates changes in the popularity of competing drugs (new versus old) used in three different fields of pharmacotherapy: migraine, gastroesophageal reflux, and mycoses. Although the pattern looks the same - a very slow (10-20 years) process of a new drug supplanting one or more old drug - there was an important difference related to the mechanism of action between triptans and triazoles on the one hand and proton-pump inhibitors on the other. Proton-pump inhibitors supplanted histamine $\mathrm{H}_{2}$ inhibitors by offering a more effective and completely new mechanism of action with a new molecular target. Triptans and triazoles are very different from proton-pump inhibitors in this regard. Triptans, which displaced ergot alkaloids (ergotamine and dihydroergotamine) in the acute treatment of migraine, act on the same receptors $\left(5-\mathrm{HT}_{1 \mathrm{~B} / 1 \mathrm{D}}\right)$ as ergot alkaloids, ${ }^{13}$ but more selectively, and thus are much less likely to cause adverse effects. This relationship between supplanting-supplanted groups of drugs for migraine is similar to what was observed in the triazoles-imidazoles competition in the treatment of mycoses (Figure 2). Both groups have the same molecular target in the fungal cell, but triazoles lack the human corticosteroid-suppression effect of imidazoles and have a broader antifungal spectrum. ${ }^{13}$ Therefore, of all new drugs developed over the past 35 years, only triptans reached the selected level of IUS - more than 50. Nevertheless, the degree of novelty characterizing the molecular target of their pain-relieving action is not very high (compared with, eg, that of protonpump inhibitors, which supplanted histamine $\mathrm{H}_{2}$ antagonists in the treatment of gastroesophageal reflux).

\section{Rate of publication growth}

The paucity of new successful drugs for the treatment of chronic pain cannot be explained by a lack of intellectual effort in the field. Table 6 indicates that for the past 35 years, publications on chronic pain grew exponentially, with 5-year increases (ranging from $24 \%$ to $60 \%$ ) always higher than that in all medicobiological areas in combination. Overall, 5 -year publication productivity in the field of chronic pain grew from 2,346 in 1979-1983 to 21,095 in 2009-2013. If migraine-related publications (the only subfield of chronic pain with a positive IUS) are compared to publications in the whole chronic pain field (Table 6), it is clear that the rate of publication growth in the whole field was not slower than in the most successful subfield. Figure 3 represents the degree of change in the number of articles on migraine in general and in the number of articles on migraine and serotonin in combination (a topic that culminated in the creation of triptans). ${ }^{24}$ It is of interest that for two 5-year periods before the first publications on sumatriptan (1979-1983 and 1984-1988) there were no increases in the number of serotonin-related articles on migraine (in contrast to increases in publications on migraine in general). However, after the first publications on sumatriptan, the number of such articles increased dramatically (especially in 1989-1993).

These results indicate that increasing intellectual effort, including research, does not necessarily lead to the discovery of more effective drugs. Some correlation between the number of publications and probability of success exists, but it is probably very low. This may be comparable to the probability related to the role of sperm count in the chance of egg fertilization: increase in the sperm count from 20 to 40 million only insignificantly increases the pregnancy rate with intrauterine insemination, ${ }^{25}$ while with intracytoplasmic sperm injection, a single sperm can be sufficient for egg fertilization. The author has previously discussed possible factors contributing to the apparent drought of novel analgesics in general. ${ }^{8}$ Undiscovered pain mechanisms or mechanisms that are already known but not yet appropriately exploited for drug development are likely the root of the problem. It is unlikely that usual increases in research effort significantly increase the probability of progress in the area of chronic pain. What kind of "intracytoplasmic sperm injection" analogy may be used in pain research to facilitate the discovery of 

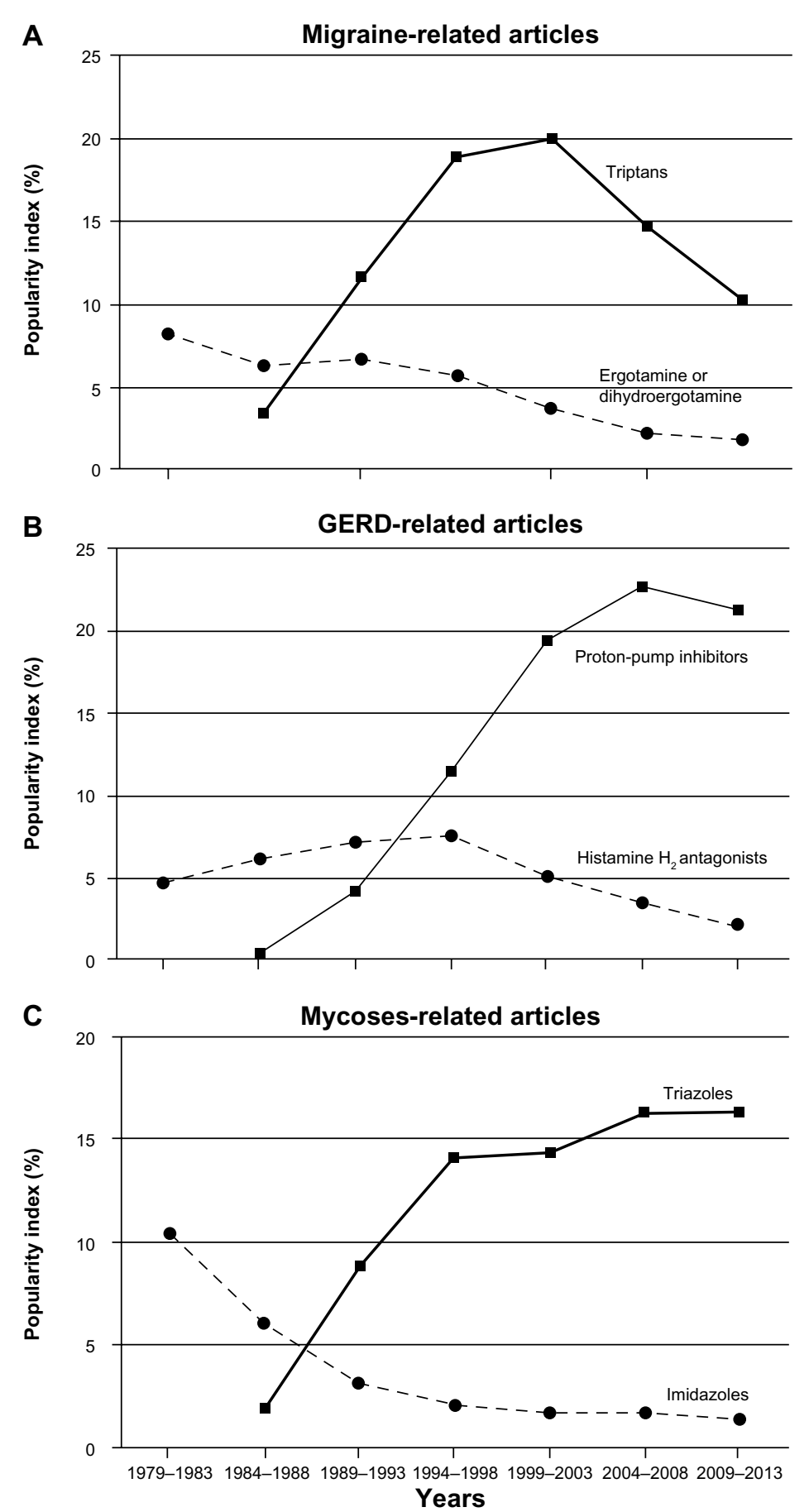

Figure 2 Time course of drug supplantation in three different fields of pharmacotherapy: migraine (A), gastroesophageal reflux (GERD) (B), and mycoses (C). The popularity index reflects the very prolonged process of an old drug(s) being supplanted by a new one.

new analgesics? Like with the chance of egg fertilization, not the number of researchers, but their individual qualities and specific features of their access to the process of drug design may be the keys to progress in this field.

The scientometric indices used to find signs of progress in the pharmacotherapy of chronic pain (PI, IC, IE, and IUS) are based on the link between the number of publications and progress in pharmacotherapy. This link is inherently weak. Its weakness is best illustrated by one of the most important findings of the present study: despite a nearly ninefold increase in the number of articles on chronic pain (from 1979-1983 to 2009-2013), there were no signs of really successful drugs in this field. In addition, this weakness is underlined by the fact that mere number of publications 


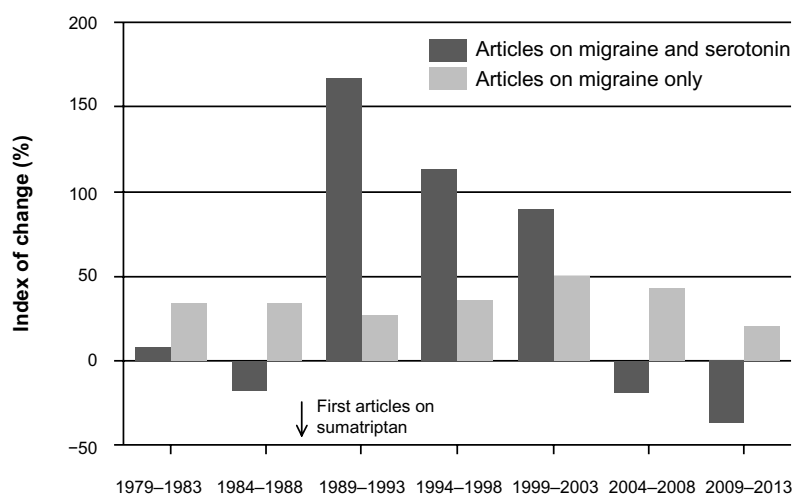

Years

Figure 3 Five-year growth rate of the number of articles on migraine, 1979-2013: migraine versus migraine AND serotonin. The index of change represents the degree of growth (percentage) in publications on a topic during a 5 -year period compared to the previous 5 -year period.

does not differentiate between publications characterizing a drug in a positive or negative way. This has been illustrated in this paper, especially in relation to the opioids. Therefore, scientometric indices should be assessed in combination with results on drug effectiveness based on good-quality evidence obtained in randomized controlled trials, as was done in the discussion on opioid treatment of chronic nonmalignant pain (systematic reviews ${ }^{16-19}$ ). The scientometric indices used in the present study have different degrees of reliability in the demonstration of a drug's progress: from the lower level with the PI and IC to the highest with the IUS.

In conclusion, very intensive effort over more than 30 years produced an exponentially increasing number of publications on chronic pain, from a 5-year rate of 2,346 articles in 1979-1983 to 21,095 articles in 2009-2013. However, despite this effort, the drugs most popular for the treatment of chronic pain actually belong to the old pharmacological classes: opioids, anticonvulsants, antidepressants, and NSAIDs. None of the studied drugs had a high IE in 2009-2013. In addition, there were no drugs that changed the PI of opioids in chronic pain, despite limited opioid effectiveness (in addition to the serious problems of safety). The IUS was positive only with triptans in a relatively small area: the acute treatment of migraine.

\section{Disclosure}

The author reports no conflicts of interest in this work.

\section{References}

1. Pizzo PA, Clark NM. Alleviating suffering 101 - pain relief in the United States. N Engl J Med. 2012;366:197-199.
2. Patel KV, Guralnik JM, Dansie EJ, Turk DC. Prevalence and impact of pain among older adults in the United States: findings from 2011 National Health and Aging Trends Study. Pain. 2013;154:2649-2657.

3. Kissin I. Can a bibliometric indicator predict the success of a drug? Scientometrics. 2011;86:785-795.

4. Kissin I, Bradley EL Jr. Top Journals Selectivity Index: is it acceptable for drugs beyond the field of analgesia? Scientometrics. 2011;88: 589-597.

5. Kissin I, Bradley EL Jr. Top Journal Selectivity Index and 'me-too' drugs. Scientometrics. 2012;91:131-142.

6. Kissin I. An early indicator of drug success: Top Journal Selectivity Index. Drug Des Devel Ther. 2013;7:93-98.

7. Correll DJ, Vlassakov KV, Kissin I. No evidence of real progress in treatment of acute pain, 1993-2012: scientometric analysis. J Pain Res. 2014;7:199-210.

8. Kissin I. The development of new analgesics over the past 50 years a lack of real breakthrough drugs. Anesth Analg. 2010;110:780-789.

9. [No authors listed]. Pain terms: a list with definitions and notes on usage. Recommended by the IASP Subcommittee on Taxonomy. Pain. $1979 ; 6: 249$

10. Merskey H, Bogduk N, editors. Classification of Chronic Pain: Description of Chronic Pain Syndromes and Definitions of Pain Terms. 2nd ed. Seattle: IASP; 1994.

11. Fishman SM, Ballantyne JC, Rathmell JP, editors. Bonica's Management of Pain. 4th ed. Philadelphia. Wolters Kluwer/Lippincot Williams \& Wilkins, 2010.

12. McMahon SB, Koltzenburg M, editors. Wall and Melzack's Textbook of Pain. 5th ed. London: Churchill Livingstone; 2006.

13. Brunton LL, editor. Goodman and Gilman's Pharmacological Basis of Therapeutics. 12th ed. New York: McGraw Hill Medical; 2011.

14. Jensen TS, Wilson PR, Rice AS, editors. Chronic Pain: Clinical Pain Management. 2nd ed. London: Hodder Arnold; 2003.

15. American Pharmacists Association. Drug Information Handbook. 22nd ed. Hudson, OH: Lexicomp; 2013.

16. Kalso E, Edwards JE, Moore RA, McQuay HJ. Opioids in chronic noncancer pain: systematic review of efficacy and safety. Pain. 2004;112: 372-380.

17. Martell BA, O’Connor PG, Kerns RD, et al. Systematic review: opioid treatment for chronic back pain: prevalence, efficacy, and association with addiction. Ann Intern Med. 2007;146:116-127.

18. Noble M, Tregear SJ, Treadwell JR, Schoelles K. Long-term opioid therapy for chronic noncancer pain: a systematic review and meta-analysis of efficacy and safety. J Pain Symptom Manage. 2008;35:214-228.

19. Nüesch E, Rutjes AW, Husni E, Welch V, Jüni P. Oral or transdermal opioids for osteoarthritis of the knee or hip. Cochrane Database Syst Rev. 2009:CD003115.

20. Finnerup NB, Otto M, McQuay HJ, Jensen TS, Sindrup SH. Algorithm for neuropathic pain treatment: an evidence based proposal. Pain. 2005;118:289-305.

21. Kissin I. Long-term opioid treatment of chronic nonmalignant pain: unproven efficacy and neglected safety? J Pain Res. 2013;6:513-529.

22. Salinas GD, Robinson CO, Abdolrasulnia M. Primary care physician attitudes and perceptions of the impact of FDA-proposed REMS policy on prescription of extended-release and long-acting opioids. J Pain Res. 2012;5:363-369.

23. Loeser JD. Five crises in pain management. Pain Clin Updates. 2012;20: $1-4$.

24. Humphrey PP, Feniuk W, Perren MJ, Beresford IJ, Skingle M, Whalley ET. Serotonin and migraine. Ann N Y Acad Sci. 1990;600: 587-598.

25. Cooper TG, Noonan E, von Eckardstein S, et al. World Health Organization reference values for human semen characteristics. Hum Reprod Update. 2010;16:231-245. 
Journal of Pain Research

Dovepress

\section{Publish your work in this journal}

The Journal of Pain Research is an international, peer-reviewed, open access, online journal that welcomes laboratory and clinical findings in the fields of pain research and the prevention and management of pain. Original research, reviews, symposium reports, hypothesis formation and commentaries are all considered for publication.

The manuscript management system is completely online and includes a very quick and fair peer-review system, which is all easy to use. Visit http://www.dovepress.com/testimonials.php to read real quotes from published authors.

Submit your manuscript here: http://www.dovepress.com/journal-of-pain-research-journal 